\title{
Cross-Train Your New Hire With a Plan and Schedule
}

\section{Zheng Ye (Lan) Yang}

To cite this article: Zheng Ye (Lan) Yang (2015) Cross-Train Your New Hire With a Plan and Schedule, Journal of Interlibrary Loan, Document Delivery \& Electronic Reserve, 25:3-5, 107-115, DOI: $10.1080 / 1072303 X .2016 .1254706$

To link to this article: http://dx.doi.org/10.1080/1072303X.2016.1254706

册 Published online: 20 Dec 2016.

Submit your article to this journal $₫$

Џ Article views: 3

Q View related articles $\square$

View Crossmark data ¿ 


\title{
GLRSC REPORTS FROM THE FIELD \\ Cross-Train Your New Hire With a Plan and Schedule
}

\author{
ZHENG YE (LAN) YANG \\ Texas A\&M University Libraries, College Station, Texas, USA
}

\section{INTRODUCTION}

Texas A\&M University (TAMU) Libraries is the first library in the nation to offer free local document delivery and interlibrary loan services to its entire campus of customers, including undergraduates, graduates, faculty, and staff members. This service has been provided since 2002. Our mission, as one might surmise, is to "get it for you," no matter where the material resides, be it in our own collections or anywhere in the world (Yang 2004, 2005, 2012).

The Document Delivery Services department of TAMU Libraries is responsible for interlibrary loan, book retrieval from library stacks for customers to pick up, and local collections scanning for our campus of over 70,000 customers. The department originally had 13 team members-five for borrowing functions, three for lending, three for local document delivery, one professional staff supervisor, one director of the department, and 11 student workers (3 FTE). In 2010, we peaked in terms of number of requests received, processing a total of 235,754 requests. Since 2011 , we have seen decrease in all three functions (borrowing, lending, and document delivery). In 2015 , we received just 156,000 requests (74,278 lending requests, 54,032 borrowing requests, and 28,064 local book retrieval and scanning requests), a 34\% decrease from 2010 (Figure 1).

Because of the downward trends in requests, the director of the department eliminated three positions (two in borrowing, one in local document delivery) after they were organically vacated due to a retirement, promotion

(c) Zheng Ye (Lan) Yang

Address correspondence to Zheng Ye (Lan) Yang, Texas A\&M University Libraries, 5000 TAMU, College Station, TX 77843-5000, USA. E-mail: Zyang@TAMU.edu

This article was accepted by the Great Lakes Resource Sharing Conference as a presentation but was not presented due to extenuating circumstances.

Color versions of one or more of the figures in the article can be found online at www.tandfonline.com/wild. 


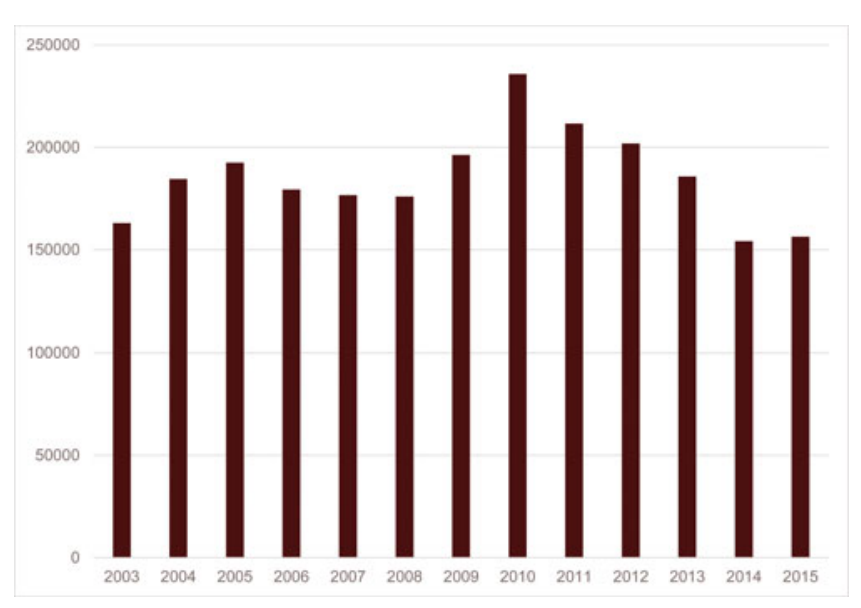

FIGURE 1 Yearly Total Requests Received From 2003-2015.

to another library department, and resignation to attend graduate school between 2011 to 2014.

On average, we now handle and process about 900 requests/items daily. The decrease in requests might be contributed to our robust electronic resources, which allow users to find fulltext online themselves, the implementation of demand driven acquisition, the installation of scanners on every single floor of the library stacks, and the improvement of our discovery services.

In the summer of 2015, two other staff members resigned, one of whom previously held a position in lending and another in local document delivery. Already running a lean team, the director did not choose to eliminate these positions. Instead, the director used their departure as an opportunity to establish a new staffing model. When the two newly vacated positions were advertised, the revised position descriptions included all three functions, namely, borrowing, lending, and local document delivery, instead of focusing on only one aspect of operation.

There are many benefits for cross training, including (but not limited to) consistent productivity even when employees are absent, decreased employee boredom, spreading employees' understanding and capabilities over a wide range of skills and tasks, and building empathy amongst team members for their colleagues. Providing employees with varied work typically results in increased productivity and satisfaction.

\section{TRAINING APPROACH AND STRATEGIES}

Why We Love Our Job

In mid-August of 2015, we hired two new staff members. On their first day of work, we explained why we love our job: 
1. Our department is regarded as the most valued and vital library service in the eyes of our customers.

2. We enjoy the detective work and resulting satisfaction of tracking down a resource.

3. We don't compete - rather, we share, help, and cooperate.

4. Seeing an item coming from South Africa/Australia/Hong Kong makes the world seem smaller.

5. We are in touch with users' real needs and make a difference in their lives.

6. The articles/books that we deliver enable our students to complete their assignments/theses and our faculty to make breakthroughs in their research efforts or secure their grants.

\section{First Things First}

After this pep talk, the supervisor gave the new hires a list of approximately 70 job tasks performed by department staff, not to overwhelm them, but to give them an idea of what they will expect to learn. They were also asked to submit a request as a user to our Get it for me system (our brand name for ILLiad). This would help them understand how the requests came to the ILLiad client as they started to learn how to process them. Finally, the supervisor asked them to read the FAQ page of the Get it for me service. This would inform them of our service coverage.

\section{Training on Borrowing Processing}

They were trained on borrowing processing first, focusing on two tasks: sending requests to other libraries to be filled and electronic delivery of articles found in TAMU Libraries databases and online resources. During the first week, the supervisor spent 2-3 hours every day sitting next to them, watching them process each request and answering questions along the way.

Figure 2 is our ILLiad borrowing module front page. Each staff member has their own specific task underneath their name. This arrangement makes clear what tasks need to be addressed should a staff member be absent; for example, if Bobbie were out for the day, the backup staff would know to take care of the requests in the queues underneath Bobbie's name. Each task has at least one back-up person.

Attention to detail is the key for our job. When we trained new staff members, we stressed that they need to check several items of information in the request, including the following: Has the patron indicated if he/she will accept other editions, or languages? What specific format has been requested-(ex. print book, audio book, ebook, or CD/DVD)? Are there any notes from the patron in the note field? Is it a rush request, in which case 


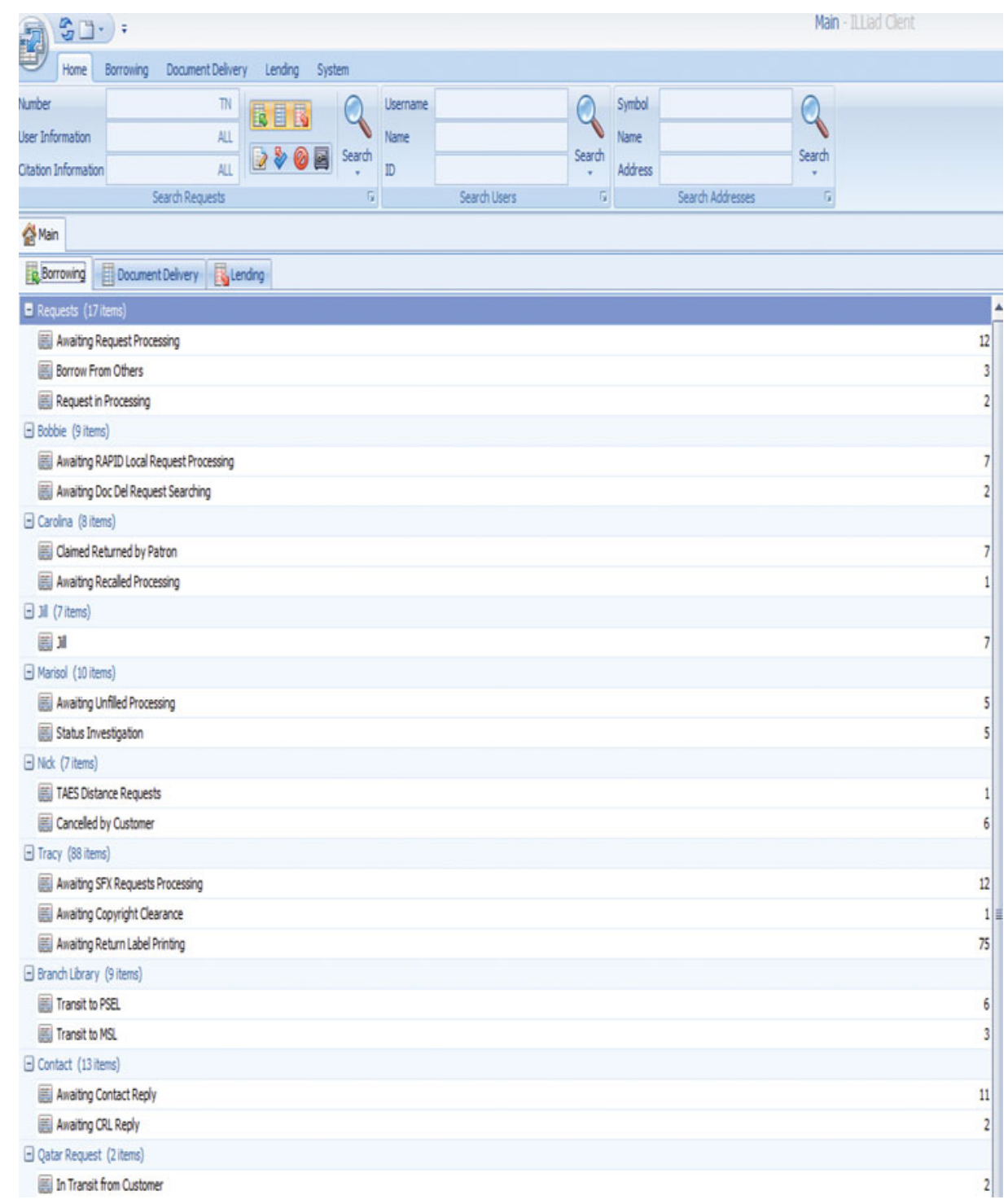

FIGURE 2 ILLiad Borrowing Module Front Page.

we need to call the lending library to alert them and put the word "rush" in the borrowing note field? For article requests, staff members were instructed to Google the article first to find open access PDFs freely available on the internet. New staff members were shown the power of keyword searching in OCLC and provided with a key MARC fields descriptions reference sheet we prepared (Appendix 1). They were instructed that searching on the ISBN or ISSN in OCLC is quicker, but a title search will bring more results depending on the complexity of the request. 


\section{Training on Lending Processing}

In week two, they were trained on lending processing. They had a tour of the library stacks, learned the library layout, the call number structures, and the locations of the re-shelving areas for each floor. We talked about our consortia group, priority processing for our consortia members, and informed them that in the case of a bad citation they should conditional the borrowing library and ask that they check the citation instead of cancelling or not filling it. If unfilled, the request will continue to the next library without being corrected, a waste of time for all parties involved. We also shared with them some OPAC search tips. They were instructed to print pull slips for stacks search, learned packaging, organizing received items, document scanning, and sending shipments via FedEx and TExpress (our state courier). We emphasized that when we return items to the lending library, to include the paperwork that was sent along with the item to help the lending library in their check-in processes. New staff members were also informed about database licenses and their effect on interlibrary loan; for example, per our contract with Elsevier, we cannot send copies of articles from its packages to libraries outside of the United States.

During the second week, they learned lending processes and spent about two hours every day on borrowing requests processing so that they wouldn't forget what they had learned the week before.

\section{Training on Local Document Delivery Processing}

On the last day of week two, moving over to our Document Delivery module training was smooth sailing. They only needed to learn how to create a hold record in Voyager circulation module after retrieving books from the stacks for our patrons, so patrons could be alerted of an available pick up. They were instructed to print pull slips, update stacks search for loans, and scan/update documents for electronic delivery.

\section{Practice on Their Own}

Starting from week three, the two new hires were on their own. We saved the screen shots during the training, so that they could be used as refreshers during processing, and they also took extensive notes for reference. A copy of step-by-step processing procedure was provided to them during the training. Both realized that taking notes enabled them to reinforce the learning, leading us to conclude that it is better to have new hires take notes during the training session rather than just give them the process procedure documents. When they ran into any uncertainty, they asked other staff, or pinged their supervisors or the director. Whenever the director saw a request that was out of norm, she would explain how she processed it, sometimes 
asking them to show her how they would tackle the request. We talked about copyright law, custom holdings, and patron privacy. They had a solid 4 months of practice after the initial training.

\section{Review and More Training}

In mid-December of 2015, the director sat down with each of the new hires and checked their progress. They both did a fantastic job. The director then showed them how to process the following tasks: awaiting copyright clearance, awaiting renewal request processing, awaiting denied renewal processing, awaiting odyssey delivery, awaiting SFX requests processing, and using OCLC blank work form to submit a request.

With the hands-on experience they'd gained over the previous four months, it took less than 30 minutes to complete the above training. We decided that after the holiday, in the spring semester, they would be trained on the following tasks: borrowing unfilled, conditional, and incoming books processing; lending conditional, renewal, and unshipped; and OCLC special messages complete and not received. They would also be trained on preparing items for faculty/staff office mail stop delivery, branch library delivery, using FedEx to ship books to distance education student's home, and checking in borrowed returned books from faculty and distance students. Overall, it took them about 8 months to feel comfortable in handling all the tasks in the department.

\section{CONCLUSION}

This model was put to test when, unexpectedly, one staff member whose responsibilities were solely in lending resigned in mid-February of 2016. Another lending staff was out for the entire week at the same time for a preplanned vacation. The two new hires just shifted and balanced their focus, giving more attention to lending in their daily work activities. It successfully alleviated any potential extra burden felt by other staff.

Their daily responsibilities include processing incoming requests in all three modules and filling in for staff absences seamlessly. After initially feeling overwhelmed by the training, after a semester they feel much less stressed and have begun to feel more confident in their abilities within the department as a whole. They are very receptive and appreciative for this training model; because work is very varied, they get to do many different things instead of focusing on only one thing every day. They are able to learn many of the department processes through incremental instruction.

This model also earned support from existing staff members. They commented that we developed a larger pool of employees who can step in when the department is short-staffed. Now each task is covered by at least five staff 
members. All tasks can be carried out throughout the day. For example, we used to process books only in the morning, because books were usually delivered at the end of shift for the staff member whose main responsibility was to process incoming borrowed books. With this new model, we can process incoming books multiple times a day. This model breaks away from traditional staffing practices in big resource-sharing/document-delivery departments, where specific staff attend to their specific responsibilities only. Based on our experiences implementing this model, we created a training schedule for our 3rd new hire (Appendix 2) who started in May 2015.

In short, this model has paid off. The new hires developed a clear understanding and appreciation for the interconnection of the department's services. They are more confident and self-reliant with a broader skill set. Department dynamics have been improved. Turnaround times have improved by .5 days for borrowing and 1 full day for lending.

\section{ACKNOWLEDGMENT}

This article is based on the proceedings of the Great Lakes Resource Sharing Conference held June 9-10, 2016 in Indianapolis, Indiana.

\section{REFERENCES}

Yang, Z. Y. (2004). Customer satisfaction with Interlibrary Loan ServiceDeliverEdocs: A case study. Journal of Interlibrary Loan, Document Delivery E Information Supply, 14(4), 79-94.

Yang, Z. Y. (2005). Providing free document delivery services to a campus of 48,000 library users. Journal of Interlibrary Loan, Documen Delivery \& Electronic Reserve, 15(4), 49-55.

Yang, Z. Y, Hahn, D., \& Thornton, E. (2012). Meeting our customers' expectations: A follow-up customer satisfaction survey after 10 years of free document delivery and interlibrary loan services at Texas A\&M University Libraries. Journal of Interlibrary Loan, Document Delivery E Electronic Reserve, 22(2), 95-110.

\section{APPENDIX 1: MARC FIELDS DESCRIPTIONS}

010: Library of Congress Catalog Number (LCCN: 12-345678)

020: International Standard Book Number (ISBN: 0123456789)

022: International Standard Serial Number (ISSN: 1234-5678)

030: CODEN (ABCDEF) - assigned by Chemical Abstracts Service

037: Source of acquisition - NTIS and ERIC documents microfiche 050: Library of Congress call number

082: Dewey Decimal call number 
086: US Documents classification/call number

100: Personal name/author

110: Corporate name

111: Meeting/Conference name

210: Abbreviated title

245: Title

260: Publication place, company, \& date.

300: Physical description - book.

362: Dates of publication/sequential designation - serials

440: Series title

502: Dissertation/thesis note

772: Parent record entry - for supplements and single issues

776: Additional physical form entry merged with alternate title

780: Preceding bibliographic record - serials

785: Succeeding bibliographic record - serials

\section{APPENDIX 2: TRAINING SCHEDULE FOR NEW HIRE}

- Week 1: Train on lending process, OPAC/Database search and floor search

- Week 2: Practice lending processing and train on opening incoming mail and distributing mail, preparing for lending outgoing packages (FedEx, Texpress, International Mail)

- Week 3: Train on printing lending pull slips, updating lending stacks search for loan and scanning for electronic delivery (Odyssey, Article Exchange)

- Week 4: Practice lending processing

- Week 5: Train on processing borrowing requests in Borrow from Others and Awaiting Request Processing queues

- Week 6-7: Practice both lending and borrowing processing

- Week 8: Train on placing hold record in Voyager circulation for book retrieval in DocDel, updating DocDel loan/article stacks search for delivery

- Week 9-12: Practice Lending, Borrowing and DocDel processing

- Week 13: Comprehensive review with the supervisor

- Week 14: Train on the following borrowing tasks:

- Awaiting Copyright Clearance

- Awaiting Renewal Request Processing

- Awaiting Denied Renewal Processing

- Awaiting Odyssey Delivery

- Users to Clear

- Awaiting SFX Requests Processing

- Using OCLC blank work form to submit request

- Week 15-17: Practice all of the above 
- Week 18-19: Train on processing incoming books for borrowing

- Week 20: Comprehensive review with the supervisor

- Week 21: Train on borrowing unfilled/conditional processing

- Week 22: Train on following lending tasks:

- Conditional request processing

- Unshipped

- Renewal request

- OCLC Special Message: Complete, Not Received

- Week 23-24: Practice all of the above

- Week 25: Comprehensive review with the supervisor

- Week 26-27: Train on following DocDel tasks:

- Monitor request queues for books to/from branch libraries

- Prepare items for faculty office and branch library delivery

- Ship books to distance education student's home via FedEx

- Check in returned books from faculty/distance students in borrowing

- Week 28-31: Practice all of the above processing

- Week 32: Comprehensive review with the supervisor 